Running head: PROSPECTIVE MEMORY AND AGEING PARADOX

Prospective memory and ageing paradox with event-based tasks: A study of young, young-old and old-old participants

\author{
Lia Kvavilashvili ${ }^{1}$, Janet Cockburn ${ }^{2}$ \& Diana E. Kornbrot ${ }^{1}$ \\ ${ }^{1}$ University of Hertfordshire \\ ${ }^{2}$ University of Reading
}

Address for correspondence:

Lia Kvavilashvili

School of Psychology

University of Hertfordshire

College Lane

Hatfield, Herts, AL10 9AB

United Kingdom

Tel. +44 (0) 1707285121

Fax $+44(0) 1707285073$

Email:L.Kvavilashvili@herts.ac.uk 


\begin{abstract}
Research on ageing and prospective memory - remembering to do something in the future - has resulted in paradoxical findings, whereby older adults are often impaired in the laboratory but perform significantly better than younger adults in naturalistic settings. Nevertheless, there are very few studies that have examined prospective memory both in and outside the laboratory using the same sample of young and old participants. Moreover, most naturalistic studies have used time-based tasks, and it is unclear whether the prospective memory and ageing paradox extends to event-based tasks. In this study, 72 young (18-30 years), 79 young-old (61-70 years) and 72 oldold (71-80 years) participants completed several event-based tasks in and outside the laboratory. Results showed that the ageing paradox does exist for event-based tasks but manifests itself differently than in time-based tasks. Thus, younger adults outperformed old-old participants in two laboratory event-based tasks, but there were no age effects for a naturalistic task completed at home (remembering to write the date and time in the upper left corner of a questionnaire). The young and old-old also did not differ in remembering to retrieve a wristwatch from a pocket at the end of the laboratory session. This indicates that the paradox may be due to differences in ongoing task demands in the lab and everyday life, rather than the location per se. The findings call for a concentrated effort towards a theory of cognitive ageing that identifies the variables that do, or do not, account for this paradox.
\end{abstract}

Keywords: Event-based prospective memory, age-prospective memory paradox, naturalistic prospective memory, laboratory prospective memory 


\section{Prospective memory and ageing paradox with event-based tasks: A study of} young, young-old and old-old participants

In everyday life, people are constantly faced by the necessity to remember a variety of prospective memory tasks such as remembering to call a dentist in the morning and meet someone at 2:00 pm (time-based tasks) or take a medication with breakfast and buy some stamps when passing a post office (event-based tasks). All these tasks involve remembering previously intended actions at appropriate occasions in future, without any explicit prompts or reminders, and are vitally important for successful everyday functioning (McDaniel \& Einstein, 2007). Investigating prospective memory and its underlying mechanisms is particularly important for older people, as failures may have serious implications for their ability to live independently and, hence, on their quality of life. Consequently, research on ageing continues to be one of the most intensively studied topics in prospective memory using both laboratory and naturalistic methods of enquiry.

In laboratory studies, reliable age effects, favouring younger adults, have often been found with a standard Einstein and McDaniel (1990) paradigm where participants have to remember to press a key once every few minutes (time-based task) or in response to particular target words (event-based task) while being busily engaged in a computerized ongoing task. Age effects have also been obtained with more incidental one-off tasks inserted into the course of laboratory session (e.g., remembering to ask for a red pen or do something at the end of a particular task) (Dobbs \&Rule, 1987; West, 1988). In contrast, naturalistic studies outside the laboratory use much longer delay intervals and tasks that require making phone calls or sending post-cards to the researcher at pre-arranged times/dates or simulating pill taking by operating small electric devices at particular times (Devolder, Brigham, \& 
Pressley, 1990; Maylor, 1990; Moscovitch, 2008; Patton \& Meit, 1983; Rendell \& Craik, 2000; Rendell \& Thomson, 1993; 1999; West, 1988). Surprisingly, almost all of these studies have shown that older adults outperform younger adults, even when using fairly complex time schedules. This contrasting pattern of findings with older adults showing impaired prospective memory in the laboratory but outperforming younger adults outside the laboratory has been termed the prospective memory and ageing paradox and presents a considerable challenge to researchers.

Despite a substantial body of research on ageing and prospective memory, systematic research on the paradox, comparing performance on laboratory and naturalistic tasks in the same sample of young and older adults, is in its infancy (Phillips, Henry, \& Martin 2008; see also Kliegel, Rendell \& Altgassen, 2008). Moreover, almost all studies on this paradox have been conducted on time-based prospective memory, due to difficulties of designing naturalistic event-based tasks. In addition, different patterns have started to emerge for time- and event-based prospective memory that merit special attention. For time-based tasks, there are only three studies that assessed the paradox in one sample of young and older adults, using naturalistic tasks of remembering to log onto a personal organizer (Rendell \& Thomson, 1999), sending a text message (Schnitzspahn, Ihle, Henry, Rendell \& Kliegel, 2011) or making a phone call (Niedzwienska \& Barzykowski, 2012) at particular times for several days. In all three studies, older adults outperformed younger adults on these tasks. In contrast, on standard laboratory time-based tasks, young participants either performed significantly better than the old (Rendell \& Thomson, 1999; Schnitzspahn et al., 2011), or there was no age effect (Niedzwienska \& Barzykowski, 2012). It is important that in Rendell and Thomson's (1999) study, the prospective memory and ageing paradox was obtained not only for participants in 
their 60 s (60-69 years), but also for participants in their 80s (80-92 years). These oldold participants outperformed the young (18-28 years) outside the laboratory, but were significantly impaired on several laboratory tasks of prospective and retrospective memory. In summary, these three studies provide strong evidence in support of the standard ageing paradox for time-based prospective memory tasks.

In contrast, the findings with naturalistic event-based prospective memory are less clear and consistent. There are only four such studies, of which, only two have examined the paradox with participants performing event-based tasks both in and outside the laboratory. Dobbs and Rule (1987) tested young (30-39 years), young-old (60-69 years) and old-old (70-99 years) participants with two different event-based tasks. ${ }^{1}$ The laboratory task was to remember to request a red pen, when asked to draw a circle and a cube later on in the session. The naturalistic task, with the same participants, involved filling in a questionnaire at home and remembering to write a date and time of completing the questionnaire in the upper left hand corner of the questionnaire. Results showed age-related declines both in the laboratory (young performed significantly better than old-old) and outside the laboratory (young were better than young-old and old-old). A similar, negative age effect was also obtained in a naturalistic e-diary study by Bailey, Henry, Rendell, Phillips and Kliegel (2010) where participants had to complete a questionnaire on their personal digital organizers in response to random beeps, and a prospective memory task was to press a key if a particular question was printed in capital letters. ${ }^{2}$

However, Rendell and Craik (2000) demonstrated a standard paradox by showing that young participants performed significantly better than the old on laboratory event-based memory as assessed by their 'Virtual Week' task, but older adults outperformed the young on comparable event-based tasks completed in 
everyday life. ${ }^{3}$ Finally, a different pattern was obtained by Niedzwienska and Barzykowski (in press), who tested a large sample of young and older adults both in and outside the laboratory with two types of event-based tasks, focal and non-focal. In focal tasks, prospective memory target events were processed as part of the ongoing activity, while in non-focal tasks, participants had to switch their attention away from the material processed in the ongoing activity to notice the non-focal target events (McDaniel \& Einstein, 2007). Results showed significant age decrements in the laboratory with both types of tasks, but no reliable age effects for either focal or nonfocal tasks outside the laboratory.

In summary, the majority of laboratory studies have shown that young adults perform significantly better than old irrespective of type of task (time- or eventbased). In sharp contrast, the naturalistic studies on time-based prospective memory have consistently demonstrated the superiority of older adults, and have, therefore, confirmed the ageing paradox for time-based tasks. However, the findings with naturalistic event-based tasks are scarce and contradictory, with two studies showing superiority of young adults, one study showing older superiority and one showing no age effect. Hence, it is unclear if the paradox extends to event-based prospective memory.

Another important question is to find whether the paradox is driven by the context in which participants are tested (laboratory vs. real life) or the type of tasks/activities they are engaged in, irrespective of the context. Age related decline in prospective memory has been obtained in few studies where participants were tested by researchers in their own homes (Huppert, Johnson \& Nickson, 2000; Logie \& Maylor, 2009; Mäntyla \& Nilsson, 1997) and no age effects have been obtained in the laboratory when using a simple prospective memory task of requesting a belonging at 
the end of the session (a sub-task of Rivermead Behavioural Memory Test, Cockburn \& Smith, 1991; Kliegel, McDaniel, \& Einstein, 2000; Martin, Kliegel \& McDaniel, 2003). These findings suggest that the paradox may not be due to the context of enquiry (lab vs. everyday life) but other variables such as ongoing task demands (see Bailey et al., 2010). Furthermore, there is evidence to suggest that in the laboratory tasks of prospective memory, age effects emerge only when young adults are compared to old-old adults (aged 70 and above), but not when they are compared to young-old adults in their 60s (e.g., Dobbs \& Rule, 1987; Zimmerman \& Meier, 2006). Therefore, to properly assess the paradox, not only it is necessary to have the same sample of young and old adults performing both the laboratory and naturalistic tasks, but older adults need to be split into groups of young-old and old-old participants, as was the case in the studies of Dobbs and Rule (1987) and Rendell and Thomson (1999).

The present study addressed these issues by examining the prospective memory and ageing paradox for laboratory and naturalistic event-based prospective memory in a large sample of young (18-30 years), young-old (61-70 years) and oldold (71-80 years) participants. All participants took part in a laboratory session where they completed several prospective and retrospective memory tasks. The effects of age on these tasks are reported in detail elsewhere (Kvavilashvili, Kornbrot, Mash, Cockburn, \& Milne, 2009). The present paper focuses on two additional prospective memory tasks, which were not reported by Kvavilashvili et al. (2009), but have implications for the prospective memory and ageing paradox. In the naturalistic task, modeled after Dobbs and Rule (1987), participants had to fill in a questionnaire at home and remember to write the date and time of completing the questionnaire in the upper left hand corner of the questionnaire. Performance on this naturalistic task was 
compared to two event-based tasks completed in the laboratory as part of the study described in Kvavilashvili et al. (2009). In the second prospective memory task, participants were asked to remove their wristwatch at the beginning of the experiment and put it away in their pocket or bag. Although no direct instructions were given to retrieve the watch afterwards, the experimenter made a note of whether participants remembered to put the watch on their wrist after the session.

If the paradox extends to event-based tasks, young participants should perform better than the old on two laboratory tasks, especially when compared to old-old participants, and young-old and old-old should perform better than the young on a naturalistic date and time task ( $c f$. Rendell \& Craik, 2000). If, however, the paradox manifests differently for event-based and time-based tasks as shown by Niedzwienska and Barzykowski (2012), then no age effect should be obtained in the naturalistic date and time task but standard (negative) age effects would emerge for laboratory tasks (at least between young and old-old participants). Finally, if the paradox is driven by type of ongoing activities, rather than the setting, then no age effects should be obtained in the wristwatch task, which participants had to complete when they were engaged in an informal chat with a researcher, mimicking everyday contexts for naturalistic tasks.

\section{Method}

\section{Participants}

The sample consisted of healthy, community residing young and older adults. There were 72 young participants ( 21 males, 51 females) whose mean age was 23.5 years ( $S D=3.6$; range 18-30), 79 young-old participants (36 males, 43 females) with a mean age of $66.1(S D=3.1$, range 61-70), and 72 old-old participants (30 males, 42 females) with a mean age of $75.1(S D=2.8$, range 71-80). All participants had English 
as their first language and received a payment of $£ 10$ (approximately \$15) for their time and travel expenses.

Table 1 lists means of background variables by age group and the results of one-way ANOVAs between these means. Vocabulary was estimated from scores on the Spot-the-Word Test of the Speed and Capacity of Language Processing Test (SCOLP; Baddeley, Emslie, \& Nimmo-Smith, 1993), and was reliably better in both young-old and old-old participants than in the young group (for both contrasts, $p<.0001)$. Test of general cognitive functioning revealed an opposite trend. Although all the old participants scored at least 24/30 on Mini Mental State Examination (MMSE; Folstein, Folsten, \& McHugh, 1975), their scores were reliably lower than in the young group ( $p_{\mathrm{s}}<.001$ for both groups of old participants). Young participants were also reliably better than young-old $(p=.04)$ and old-old $(p=.001)$ on the Speed of Comprehension Test of the SCOLP, and had spent significantly more years in full time education ( $p_{\mathrm{s}}<.001$ for both groups of old participants). The difference between the two old groups was also significant in the expected direction, $p=.01$.

\section{Materials and procedure}

Participants were tested individually in a session lasting one and a half to two hours. In this session, they completed several cognitive tasks and questionnaires (for details, see Kvavilashvili et al., 2009) including the three event-based prospective memory tasks. In the first task participants were asked to remove their wristwatch at the beginning of the session and put it away in their pocket or a bag. No explicit instructions were given to retrieve the watch at the end of the session. However, the experimenter made a note of whether the participants retrieved the watch after the session. The response was counted as correct if the watch was retrieved in the lab or while participants were being escorted out of the building where the study took place. 
The second, event-based 'colour paper' task involved informing participants at the beginning of the session that some of the paper and pencil tasks throughout the session would be printed on coloured sheets of paper. When presented with one of these coloured sheets, participants had to remember to write the name of that colour anywhere on the page as soon as they noticed that the paper was coloured. It was specifically pointed out to the participants that they would not receive any further hints or reminders about this task, and that they had to remember it themselves. Although participants encountered three tasks printed on a coloured sheet of paper (pale green, pale yellow and peach) performance on this task was measured on the basis of their response (yes/no) to the first target opportunity (recognition memory test printed on green paper), which occurred approximately 10 minutes from receiving the prospective memory instructions, and took about 5-7 minutes to complete. This was done to make performance on the colour task more comparable with the remaining prospective memory tasks presented in this paper, which were all based on a single target opportunity. Instructions for the third event-based prospective memory task were received at the beginning of the second half of the session, after a brief coffee break. Specifically, participants were told that if at some point they were asked to copy a geometric figure, they had to request a red pen with which to draw it. In approximately 10 minutes, the experimenter gave the participants a sheet of paper with two interlocked pentagons (a sub task of MMSE) and asked them to copy this geometric figure in the space underneath. Participants had to remember to ask for a red pen before starting to copy the figure.

At the end of the session, participants were given a booklet of two questionnaires (which were part of another study), and were asked to fill them in at home and send them back (in a pre-paid envelope) within the next few days. The 
experimenter then gave the following prospective memory instructions for the naturalistic 'date and time' task: "It is very important for us to know the date and time when the questionnaires are answered so could you please write this on the front page. In order to help us to sort and analyse the data efficiently could you please write the time and the date here in the upper left hand corner of the front page?" and the experimenter pointed to the correct location on the page. Participants then put the questionnaire in the pre-paid envelope, received the payment and were debriefed before being escorted by the researcher out of the building.

\section{Results}

All 223 participants completed the laboratory colour and red pen tasks. However, 20 participants (11 young, 5 young-old and 4 old-old) did not return their questionnaires, ${ }^{4}$ therefore, with the exception of wristwatch task (see below), the analyses reported in this section were conducted on 61 young, 74 young-old and 68 old-old participants. Post experimental probing of those participants who forgot to perform the laboratory colour or the red pen task revealed that two young-old and two old-old participants were unable to recall prospective memory instructions for the red pen task. However, the exclusion of these participants did not change the results, hence, they were retained in the analyses. Similarly, the exclusion of 22 participants (1 young, 7 young-old and 14 old-old) whose MMSE scores were below 27 also did not change the pattern of results reported below.

For each prospective memory task, participants' response was scored as ' 1 ' if they remembered to carry out the task, and ' 0 ' if they forgot. Following Dobbs and Rule (1987), two scores were calculated for the date and time task, the lenient score (if the participant remembered to write any of the requested details in the correct or incorrect location) and the strict score (if the participant wrote both the date and time 
in the correct location). Although performance was higher for lenient scores in all age groups, the patterns of findings were identical and therefore, only the results for lenient scores are reported. This is because the lenient score captures more accurately the prospective "remembering to remember" component of event-based tasks.

Since the data were binary, logistic regression was used for all inferential tests (Dixon, 2008; Jaeger, 2008). Figure 1 shows performance for the four prospective memory tasks (colour paper, red pen, date and time, and wristwatch) in the logit $=$ $\ln (p) /(1+\ln (p)$ metric used for inferential tests. The right panel shows performance as the proportion of participants who remembered to perform the task (a more prevalent measure used in prospective memory literature). Table 2 shows results of omnibus tests for each task separately and the follow up tests comparing different age groups. The results of one-way ANOVAs on the proportional scores are also reported.

For both laboratory tasks, there was a significant effect of age. Post hoc comparisons for both tasks showed that performance of old-old participants was worse than young and young-old participants, who did not differ from each other. By contrast, the naturalistic date and time task (lenient) showed no significant omnibus age effect, and no significant post hoc pairwise comparisons. The power to detect a medium effect size $\chi^{2}$ (non-centrality parameter $=11.4$ ) was .87 . The noncentrality parameter for an ANOVA with medium effect size and 3 equal groups with the smallest group of 61 participants, also gives a non-centrality of 11.4.

In order to check that the differences in age patterns between tasks were statistically reliable, a two factor logistic regression was conducted with age group (young, young-old, old-old) as a between subjects factor and tasks (colour paper, red pen, date and time) as a within subjects factor. The age by task interaction was 
significant $\chi^{2}(4)=11.41 p=.002$, confirming the contrasting patterns for laboratory and naturalistic event-based tasks.

Data for the wristwatch task were available for 150 participants (38 young, 60 young-old and 52 old-old). Data was missing for 48 participants not wearing a watch (29 young, 12 young-old and 7 old-old), and for 25 participants the experimenter forgot to record participant's action, due to prospective memory failure. ${ }^{5}$ Analysis of the wristwatch task resulted in a significant age effect. Post hoc tests revealed that this was due to the young performing significantly worse than the young-old (Table 2).

\section{Discussion}

The findings from this study clarify several issues in relation to prospective memory and ageing paradox and have implications for research on prospective memory and cognitive ageing in general. The most important result was that the ageing paradox was confirmed for event-based tasks. In laboratory, young participants performed significantly better than old-old in two event-based tasks. In sharp contrast, no reliable age effects emerged for the naturalistic date and time task irrespective of type of scoring used. Moreover, this non-significant age effect was not due to a lack of power or above average cognitive abilities of our elderly sample. If anything, they showed typical age related declines in the speed of processing and retrospective memory and had fewer years in education than young adults (see Table 1 and Kvavilashvili et al., 2009).

This pattern of findings fully replicates the results of Niedzwienska and Barzykowski's (2012) who also tested a single sample of young and older adults, but used a different set of laboratory and naturalistic event-based tasks. Thus, participants who regularly watched evening news on TV, had to call the researcher when a name of a Polish politician was mentioned for the first time during the evening news (a non- 
focal task) or when they saw a map of Poland at the end of the news during the weather forecast (a focal task). Each task was completed 4 times on alternating days, while in our study participants completed the date and time task only once and did not even know that their prospective memory was being investigated. Despite these differences, no reliable age effects were obtained in either study.

Taken together, results appear to provide strong initial support for the idea that the paradox may manifest itself differently for naturalistic time- and event-based tasks, with no significant age effects emerging for event-based tasks but older adults outperforming the young on time-based tasks. From the standpoint of general theory of cognitive ageing (Craik, 1986), no effects of age are expected for cognitive tasks which rely on automatic retrieval processes like, for example, tasks measuring implicit memory (Light, 1991; Nilsson, Bäckman, Erngrund, Nyberg, Adolfsson et al., 1997). If in everyday life, prospective memory relies primarily on automatic retrieval processes and/or incidental cues in the environment, as stipulated by multiprocess theory of McDaniel and Einstein (2007) (see also Holbrook \& Dismukes, 2009; Kvavilashvili \& Fisher, 2007), then no age effects should emerge in naturalistic prospective memory tasks. This indeed appears to be the case with eventbased tasks used both in our and Niedzwienska and Barzykowski’s (2012) studies. Future research should therefore focus on finding out what compensatory mechanisms are set in motion in everyday life of older adults so that they can outperform younger adults on time-based tasks. Although both reminders and levels of motivation have been offered as an explanation for ageing paradox with time-based tasks, Niedzwienska and Barzykowski's (2012) found no evidence to suggest that older adults were more motivated and/or used more strategies for remembering time- than 
event-based tasks. Therefore, some other variable(s) may be at play that differentially affects older adults' performance on naturalistic time- and event-based tasks.

Another set of interesting findings refers to the laboratory wristwatch task, in which no age effects were obtained between young and old-old participants but young-old participants performed significantly better than young adults. This finding is in sharp contrast with negative age effects in the laboratory colour paper and red pen tasks, and suggests that the prospective memory and ageing paradox may not necessarily be about the context of enquiry (lab vs. real life) but rather about types of tasks participants have to carry out. Of key importance may be whether the ongoing tasks are experimenter controlled or not (e.g., see Bailey et al., 2010; Logie \& Maylor, 2009). Indeed, in the red pen and the colour paper task, participants were engaged in carrying out various experimenter controlled cognitive tasks when they encountered the target events (even though the ongoing tasks were self-paced, $c f$. Niedzwienska \& Barzykowski, 2012). By contrast, participants had to remember to retrieve the wristwatch at the end of the session while they were engaged in informal conversation with the researcher both inside the lab and when being escorted outside the building where the session took place. This might be regarded as a cognitively less demanding activity and something that they do on a daily basis.

It appears that presence or absence of negative age effects can be observed in both settings depending on task demands. The importance of ongoing task demands has been recently highlighted in two laboratory studies in which negative age effects were eliminated when the ongoing task demands were significantly reduced (Rendell, McDaniel, Forbes \& Einstein, 2007), or when the performance levels on the ongoing tasks were controlled for (Schnitzspahn et al., 2011). Taken together, these results suggest that ongoing task difficulty may be one of the variables contributing to 
paradoxical findings and more systematic research is needed into this variable.

Despite interesting findings, some caution is needed when interpreting results in relation to the naturalistic date and time task and the laboratory wristwatch task. Thus, the date and time task was only loosely matched to one of the two laboratory tasks - the colour paper task. Although in both tasks participants had to remember to do something while working on a sheet of paper, in the colour task, the first coloured paper was encountered in approximately 10 minutes after receiving instructions, while in the date and time task, the delay was much longer, 48 hours on average. However, to our knowledge, none of the other studies on the ageing paradox have managed to equate the tasks on this aspect. Moreover, the only existing laboratory study of ageing that used time delays of several days (Salthouse et al., 2004, p. 1138) found significant age effects, suggesting that different time delays may not be responsible for the contrasting patterns of obtained in and outside of the laboratory.

Furthermore, the laboratory and naturalistic date and time tasks were not entirely similar in terms of importance of the task. Following Dobbs and Rule (1987), who used a special cover story to emphasize the importance of the date and time task, we also told the participants that it was 'very important' for us to know date and time when they filled in the questionnaire. In the colour task, we pointed out to participants that they had to remember this task themselves as no further hints or reminders would be provided in the course of the experiment. We assumed that such instructions would have alerted participants to the importance of remembering the task themselves. In retrospect, however, it would have been beneficial to use the words "very important" for the colour paper task as well. Despite these limitations, the date and time task was a simple, one-off task resembling types of tasks that people carry out in their everyday life, which put minimal burden on participants' memory 
for prospective memory instructions. Moreover, none of the participants attempted to make a written note of this task either in the lab or afterwards when the experimenter escorted them out of the building. From participants' perspective, their task was to fill in the questionnaire and send it back to the researcher. They could have easily used reminders to accomplish this task (e.g., leaving a questionnaire on a kitchen table). However, it was unlikely that they set up extra reminders for the additional (and simple) date and time task upon their arrival at home.

For the laboratory wristwatch task, the data of 73 participants was missing. Nevertheless, the number of participants in each age group was still relatively large varying from 38 (young) to 60 (young old) (see Table 2). Another problem was that participants were asked to put away their watch in a pocket or bag and there was no explicit request from the researcher to put back the watch after the experiment. The task was implicit in that participants themselves had to form this intention when they were putting away the watch. It is therefore, unclear whether the age effects that were obtained were due to young and old-old adults being less likely than young-old to form such intention, or whether all participants formed this intention but young-old adults were more likely to remember it. Although this cannot be ascertained, it is important that young and old-old participants did not differ in their performance on this task. The findings also raise an intriguing possibility that the conscious formation of intention to act may not always be necessary for successful remembering as stipulated in the prospective memory literature (Ellis, 1996; Kvavilashvili \& Ellis, 1996; Smith, 2008). For example, it is possible that participants simply assumed that they would put the watch back without explicitly thinking about when and how they would do it. According to Dismukes (2008), who analysed prospective memory errors in aviation and everyday settings, implicit intentions may be formed when one gets 
interrupted and the "intention" to resume the interrupted activity may later be retrieved upon encountering some accidental cues in the environment. Moreover, results of a diary study by Holbrook and Dismukes (2009) showed that on $23 \%$ of recorded occasions participants reported that they did not much think about intention, but just assumed they would remember it, and on further $35 \%$ of occasions participants reported making a 'mental note' to perform intention without specifically thinking about how, when or where they would perform it. Clearly, investigating the formation and execution of such implicit intentions in everyday and laboratory settings as a function of age will be an interesting avenue for future research.

In summary, results of the present study show that while age effects (favouring the young over the old-old participants) were obtained with two laboratory tasks of event-based memory, performance on a simple naturalistic event-based task did not decline with age. In addition, the absence of age effects between young and old-old participants on the wristwatch task in the laboratory emphasizes the importance of ongoing task demands as one of the possible key variables in solving the prospective memory and ageing paradox. The results clearly show that more intensive and systematic research is needed to generate a theoretical understanding of the reasons behind the prospective memory and ageing paradox and why it may manifest differently for event- and time-based tasks. 


\section{References}

Baddeley, A., Emslie, H., \& Nimmo-Smith, I. (1993). The spot-the-word test: A robust estimate of verbal intelligence based on lexical decision. British Journal of Psychology, 32, 55-65.

Bailey, P. E., Henry, J. D., Rendell, P. G., Phillips, L. H., \& Kliegel, M. (2010). Dismantling the "age-prospective memory paradox": The classic laboratory paradigm simulated in a naturalistic setting. The Quarterly Journal of Experimental Psychology, 63, 646-652.

Cockburn, J., \& Smith, P. T. (1991). The relative influence of intelligence and age on everyday memory. Journal of Gerontology: Psychological Sciences, 46, 31-36.

Craik, F. I. M. (1986). A functional account of age differences in memory. In F. Clix, \& H. Hagendorf (Eds.), Human memory and cognitive capabilities: Mechanisms and performances (pp. 409-422). Amsterdam: Elsevier.

Devolder, P. A., Brigham, M. C., \& Pressley, M. (1990). Memory performance awareness in younger and older adults. Psychology and Aging, 5, 291-303.

Dismukes, K. (2008). Prospective memory in everyday and aviation settings. In M.

Kliegel, M. A. McDaniel, and G. O. Einstein (Eds.), Prospective memory: Cognitive, neuroscience, developmental, and applied perspectives (pp. 411-431) New York: Lawrence Erlbaum Associates.

Dixon, P. (2008). Models of accuracy in repeated-measures designs. Journal of Memory and Language, 59, 447-456.

Dobbs, A. R., \& Rule, B. G. (1987). Prospective memory and self-reports of memory abilities in older adults. Canadian Journal of Psychology, 41, 209-222.

Einstein, G. O., \& McDaniel, M. A. (1990). Normal ageing and prospective memory. 
Journal of Experimental Psychology: Learning Memory and Cognition, 16, 717-726.

Ellis, J. A. (1996). Prospective memory or the realization of delayed intentions: A conceptual framework for research. In M. Brandimonte, G. O. Einstein, \& M. A. McDaniel (Eds.), Prospective memory: Theory and applications (pp. 1-22). Mahwah, NJ: Erlbaum.

Folstein, M. F., Folstein, S. E., \& McHugh, P. R. (1975). "Mini-Mental State”: a practical method for grading the cognitive state of patients for the clinician. Journal of Psychiatric Research, 12, 189-198.

Holbrook, J., \& Dismukes, K. (2009). Prospective memory in everyday tasks. In Proceedings of the Human Factors and Ergonomics Society $53^{\text {rd }}$ Annual Meeting (pp. 590-594).

Huppert, F. A., Johnson, T., \& Nickson, J. (2000). High prevalence of prospective memory impairment in the elderly and in early-stage Dementia: Findings from a population-based study. Applied Cognitive Psychology, 14, S63-S81.

Jaeger, T. F. (2008). Categorical data analysis: Away from ANOVAs (transformation or not) and towards logit mixed models. Journal of Memory and Language, $59,434-446$.

Kliegel, M., McDaniel, M. A., \& Einstein, G. O. (2000). Plan formation, retention, and execution in prospective memory: A new approach and age-related effects. Memory \& Cognition, 28, 1041-1049.

Kliegel, M., Rendell, P. G., \& Altgassen, M. (2008). The added value of an applied perspective in cognitive gerontology. In S. M. Hofer \& D. F. Alwin (Eds.) Handbook of cognitive aging: Interdisciplinary perspectives (pp. 587-602). Thousand Oaks: Sage Publications. 
Kvavilashvili, L., \& Ellis, J. (1996). Varieties of intention: Some distinctions and classifications. In M. Brandimonte, G. Einstein, \& M. McDaniel (Eds.), Prospective memory: Theory and Applications (pp. 23-51). Hillsdale, NJ: Erlbaum.

Kvavilashvili, L., \& Fisher, L. (2007). Is time-based prospective remembering mediated by self-initiated rehearsals?: Role of cues, ongoing activity, age and motivation. Journal of Experimental Psychology: General, 136, 112-132.

Kvavilashvili, L., Kornbrot, D. E., Mash, V., Cockburn, J., \& Milne, A. (2009). Differential effects of age on prospective and retrospective memory tasks in young, young-old and old-old adults. Memory, 17, 180-196.

Light, L. L. (1991). Memory and aging: Four hypothesis in search of data. Annual Review of Psychology, 42, 333-376.

Logie, R. H., \& Maylor, E.A. (2009). An internet study of prospective memory across adulthood. Psychology and Aging, 24, 767-774.

Martin, M., Kliegel, M., \& McDaniel, M. A. (2003). The involvement of executive functions in prospective memory performance of adults. International Journal of Psychology, 38, 195-206.

Maylor, E. (1990). Age and prospective memory. Quarterly Journal of Experimental Psychology, 42A, 471-493.

Mäntylä, T., \& Nilsson, L-G. (1997). Remembering to remember in adulthood: A population-based study on aging and prospective memory. Aging, Neuropsychology, and Cognition, 4, 81-92.

McDaniel, M. A., \& Einstein, G. O. (2007). Prospective memory: An overview and synthesis of an emerging field. Los Angeles: Sage Publication.

Moscovitch, M. (2008). Commentary: A perspective on prospective memory. In M. 
Kliegel, M. A. McDaniel, and G. O. Einstein (Eds.), Prospective memory: Cognitive, neuroscience, developmental, and applied perspectives (pp. 309-320) New York: Lawrence Erlbaum Associates.

Niedzwienska, A., \& Barzykowski, K. (2012). The age prospective memory paradox within the same sample in time-based and event-based tasks. Aging, Neuropsychology, and Cognition, 19, 58-83.

Nilsson, L-G., Bäckman, L., Engrund, K., Nyberg, L., Adolfsson, R., et al. (1997). The Betula prospective cohort study: Memory, health and aging. Aging, Neuropsychology, and Cognition, 4, 1-32.

Patton, G. W. R., \& Meit, M. (1993). Effect of ageing on prospective and incidental memory. Experimental Aging Research, 19, 165-176.

Phillips, L. H., Henry, J. D., \& Martin. M. (2008). Adult aging and prospective memory. In M. Kliegel, M. A. McDaniel, \& G. O. Einstein (Eds.). Prospective memory: Cognitive, neuroscience, developmental and applied perspectives (pp. 161-185). New York: Lawrence Erlbaum Associated.

Rendell, P.G., \& Craik, F. I. M. (2000). Virtual week and actual week: Age-related differences in prospective memory. Applied Cognitive Psychology, 14, S43-62.

Rendell, P. G., McDaniel, M. A., Forbes, R. D., \& Einstein, G. O. (2007). Age-related effects in prospective memory are modulated by ongoing task complexity and relation to target cue. Aging, Neuropsychology, and Cognition, 14, 236-256.

Rendell, P. G., \& Thomson, D. M. (1993). The effect of ageing on remembering to remember: An investigation of simulated medication regimens. Australian Journal of Ageing, 12, 11-18.

Rendell, P. G., \& Thomson, D. M. (1999). Aging and prospective memory: 
Differences between naturalistic and laboratory tests. Journal of Gerontology: Psychological Sciences, 54B, 256-269.

Salthouse, T. S., Berish, D. E., \& Siedlecki, K. L. (2004). Construct validity and age sensitivity of prospective memory. Memory and Cognition, 32, 1133-1148.

Schnitzspahn, K. M., Ihle, A., Henry, J. D., Rendell, P., \& Kliegel, M. (2011). The age-prospective memory paradox: an exploration of possible mechanisms. International Psychogeriatrics, 23, 583-592.

Smith, R. E. (2008). Connecting the past and the future: Attention, memory and delayed intentions. In M. Kliegel, M. A. McDaniel, \& G. O. Einstein (Eds.). Prospective memory: Cognitive, neuroscience, developmental and applied perspectives (pp. 29-52). New York: Lawrence Erlbaum Associated.

West, R. L. (1988). Prospective memory and aging. In M. M. Gruneberg, P. E. Morris, \& R. N. Sykes (Eds.), Practical aspects of memory: Current research and issues (vol. 2) (pp. 119-125). Chichester, England: Wiley.

Zimmerman, T. D., \& Meier, B. (2006). The rise and decline of prospective memory performance across the lifespan. The Quarterly Journal of Experimental Psychology, 59, 2040-2046. 


\section{Author Note}

Lia Kvavilashvili, and Diana Kornbrot, University of Hertfordshire (UK), Janet Cockburn, University of Reading (UK).

Research presented in this paper was supported by a grant to Lia Kvavilashvili Diana Kornbrot, Janet Cockburn and Alan Milne from the Economic and Social Research Council (UK). We are grateful to Veronica Mash and Fiona Kyle for testing participants and data entry. Portions of research described in this paper were presented at the Cognitive Aging Conference in April, 2010 (Atlanta, USA). Correspondence concerning this article should be addressed to Lia Kvavilashvili, School of Psychology, University of Hertfordshire, College Lane, Hatfield, Herts, AL10 9AB, UK. Email: L.Kvavilashvili@herts.ac.uk 


\section{Footnotes}

${ }^{1}$ Two additional groups of middle-aged participants were also used in this study (4049 years and 50-59 years) but their performance did not reliably differ from young (30-39 years) participants.

${ }^{2}$ In this study, participants were not tested on laboratory event-based tasks.

${ }^{3}$ Note that in this study the same sample of older adults performed both the virtual week and naturalistic tasks but two different groups of young adults were tested across the two settings.

${ }^{4}$ Although more young participants $(15 \%)$ did not return the questionnaire than either young-old $(6 \%)$ or old-old participants $(6 \%)$, this difference was not statistically significant, $\chi^{2}(2)=5.21, p=.07$. There were also no age differences in the number of days it took participants to send back the questionnaires $(\mathrm{F}<1)$. Irrespective of age, the majority of questionnaires (76\%) were sent back within 48 hours with only $4 \%$ of questionnaires being returned later than 7 days from the experiment.

${ }^{5}$ It is interesting that similar lapses of prospective memory have been reported by other researchers (see McDaniel \& Einstein, 2007, p. 135; Salthouse, Berish \& Siedlecki, 2004, p. 1141). 


\section{Table 1}

Participants' Mean Scores and Standard Deviations on Background Variables as a

Function of Age Group, and the Results of Inferential Tests for Age Differences.

\begin{tabular}{|c|c|c|c|c|c|c|}
\hline \multirow[t]{2}{*}{ Variable } & \multirow[t]{2}{*}{ Parameter } & \multicolumn{3}{|c|}{ Age Group } & \multirow[t]{2}{*}{$F(2,220)$} & \multirow[t]{2}{*}{ Effect } \\
\hline & & Young & Young-Old & Old-Old & & \\
\hline $\mathrm{N}$ & & 72 & 79 & 72 & & \\
\hline $\begin{array}{l}\text { Vocabulary: } \\
\text { SCOLP - }\end{array}$ & Mean & 48.58 & 53.19 & 52.92 & 25.99 & 0.19 \\
\hline Spot-The-Word & SD & 4.25 & 4.16 & 4.62 & & \\
\hline \multirow[t]{2}{*}{ MMSE } & Mean & 29.06 & 28.23 & 27.64 & 25.99 & 0.19 \\
\hline & SD & 0.96 & 1.28 & 1.31 & & \\
\hline \multirow{2}{*}{$\begin{array}{l}\text { Speed: } \\
\text { SCOLP-Speed of } \\
\text { Comprehension }\end{array}$} & Mean & 74.26 & 69.32 & 64.06 & 11.82 & 0.1 \\
\hline & SD & 13.15 & 13.6 & 10.8 & & \\
\hline \multirow{2}{*}{$\begin{array}{l}\text { Years of } \\
\text { education }\end{array}$} & Mean & 14.01 & 12.43 & 11.35 & 23.83 & 0.18 \\
\hline & SD & 2.23 & 2.53 & 2.21 & & \\
\hline
\end{tabular}

Note: the effect size is measured by partial $\eta^{2}$. 


\section{Table 2}

Inferential statistics for performance on each task separately as a function of age group (young vs. young-old vs. old-old).

\begin{tabular}{|c|c|c|c|c|c|c|}
\hline \multirow[t]{2}{*}{ Task } & \multirow[t]{2}{*}{ Test } & \multirow[t]{2}{*}{$\mathrm{N}$} & \multicolumn{2}{|l|}{ Logit } & \multicolumn{2}{|c|}{ ANOVA $^{C}$} \\
\hline & & & $\chi^{2}$ & $\begin{array}{c}p \\
\text { (null) }\end{array}$ & $\mathrm{F}$ & $\begin{array}{c}p \\
\text { (null) }\end{array}$ \\
\hline \multirow[t]{4}{*}{ Colour paper } & Omnibus & 203 & 11.81 & $.003^{b}$ & 6.39 & .002 \\
\hline & Young vs. $60 \mathrm{~s}^{\mathrm{a}}$ & 61 & 0.48 & .491 & 0.72 & .491 \\
\hline & $60 \mathrm{~s}$ vs. $70 \mathrm{~s}$ & 74 & 10.25 & .001 & 5.52 & .006 \\
\hline & 70s vs. Young & 68 & 13.00 & .000 & 7.65 & .001 \\
\hline \multirow[t]{4}{*}{ Red pen } & Omnibus & 203 & 13.28 & .001 & 7.76 & .001 \\
\hline & Young vs. 60s & 61 & 3.25 & .071 & 2.40 & .100 \\
\hline & 60 s vs. 70 s & 74 & 4.60 & .032 & 4.79 & .030 \\
\hline & 70s vs. Young & 68 & 12.20 & .000 & 10.31 & .000 \\
\hline \multirow[t]{4}{*}{ Date \& time } & Omnibus & 203 & 1.96 & .375 & 0.99 & .373 \\
\hline & Young vs. 60s & 61 & 1.43 & .232 & 1.56 & .218 \\
\hline & 60s vs. $70 \mathrm{~s}$ & 74 & 0.00 & .979 & 0.02 & .980 \\
\hline & 70s vs. Young & 68 & 1.42 & .233 & 1.56 & .218 \\
\hline \multirow[t]{4}{*}{ Wrist watch } & Omnibus & 150 & 6.39 & .041 & 3.37 & .037 \\
\hline & Young vs. 60s & 38 & 6.37 & .012 & 5.20 & .011 \\
\hline & 60 s vs. 70 s & 60 & 1.48 & .223 & 1.54 & .224 \\
\hline & 70s vs. Young & 52 & 2.00 & .158 & 1.94 & .154 \\
\hline
\end{tabular}

Note a. $60 \mathrm{~s}=$ young-old $; 70 \mathrm{~s}=$ old-old

Note $b . \quad$ Bold $=p($ null $)<.05$, bold italic $=.10>p($ null $)>.05$

Note c. Inferential statistics using ANOVA are shown for comparison purposes 
Prospective memory and ageing paradox 28

Figure captions

Figure 1. The effect of age and task on performance. Solid lines standard laboratory event-based tasks, dashed lines - date and time task and wristwatch tasks. Triangles = colour paper; squares = red pen; diamonds = date and time, lenient; circles $=$ wristwatch . 

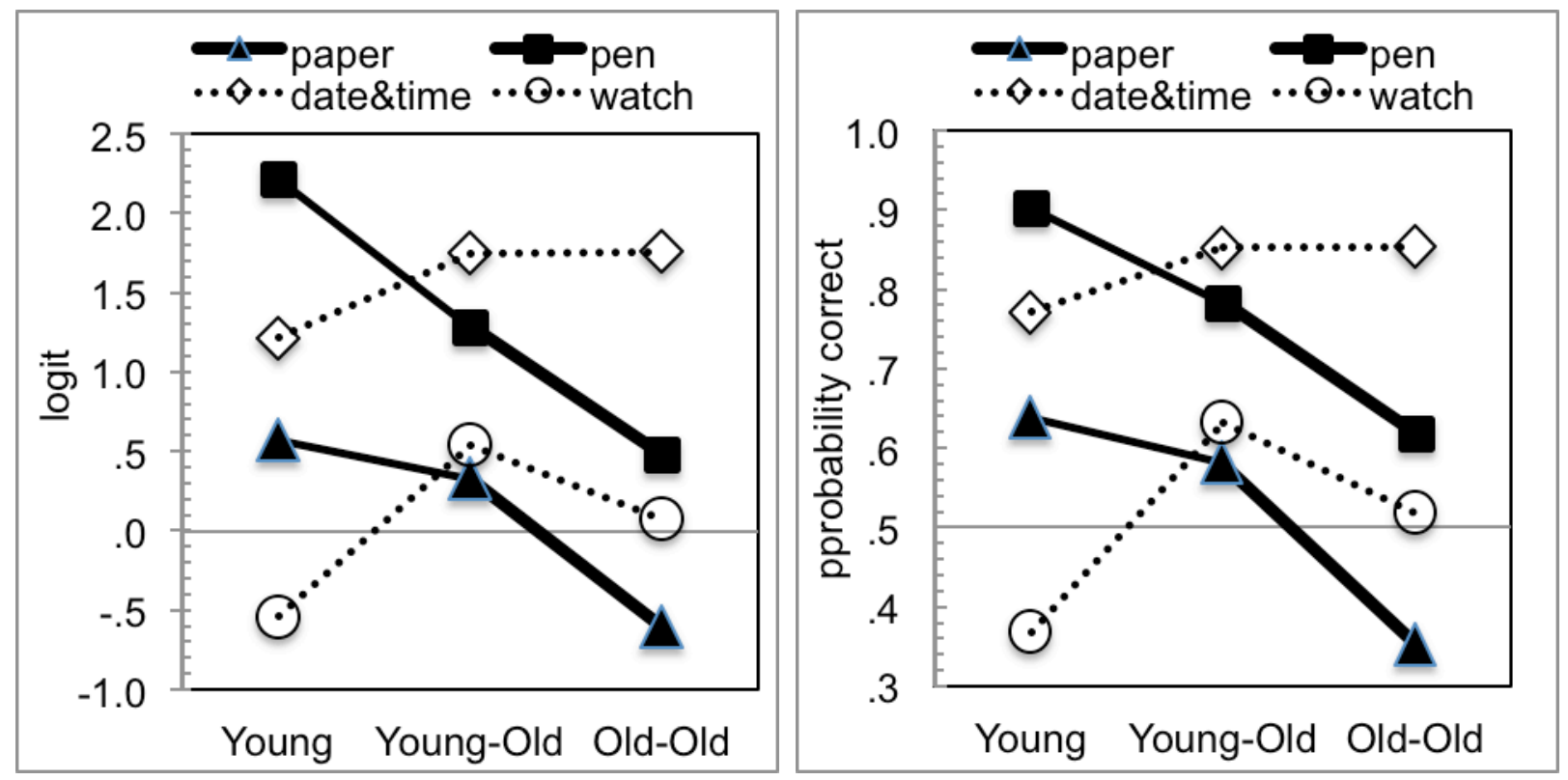